\title{
Metaphysical Foundationalism: a New Form of Justification
}

\author{
Kulieshov Aleksandr \\ Cherkasy State Technological University, \\ Department of Philosophical and Political Sciences, PhD in Philosophy, Associate Professor, Ukraine
}

\begin{abstract}
A new set of metaphysical arguments in favour of fundamental reality is proposed in the article. For this purpose the notion of the state of the world is introduced. The standard concept of grounding underlying metaphysical foundationalism is taken into account. The correspondence of the new notion and the initial principles of metaphysical fundamentalism are confirmed. The proof of fundamental reality existence is represented based on formulated principles and empirical data.
\end{abstract}

Keywords: metaphysical fundamentalism; grounding relation; entity; state of the world; fundamental reality.

UDC 141

DOI: http://dx.doi.org/10.22178/pos.17-3

\section{LCC Subject Category: BF1-990}

\section{Introduction}

One cannot but assess positively the revival of metaphysics that began within the sphere of philosophy in the second half of the twentieth century. Still more positive is the fact of the growing interest of contemporary metaphysicians to traditional metaphysics. In this context, the question of fundamental reality, the alleged basis of everything in the world, is gradually shifting to the centre of philosophical discussions. This is a natural process, since the elaboration of a certain view on fundamental reality is inevitable and necessary if we want to have holistic knowledge about the world. Avoiding this question, we will constantly bump into the invisible barrier in the process of knowledge building and this will make useless all our attempts to create a unified picture of reality. Knowledge will always break up into straggling fragments, retaining the order only within the separate subject areas of science.

The most advanced results in the study of reality foundations have been achieved recently by analytical philosophy. It may be said primarily about the concept of metaphysical fundamentalism, which has been formed and acquired features of stability and respectability over the past two decades. It is therefore only natural that this concept became the basis for the reasoning in the article. The main constitutive principle of metaphysical fundamentalism is the recognition of the two kinds of reality in our world - fundamental and non-fundamental. The first is independent of the second and in a sense self-existing. The sec- ond depends in its existence on the first and is determined (in varying degrees) by it. The above principle is not an axiom, it needs to be confirmed.

The purpose of the article is to build a new argumentation for the existence of fundamental reality in our world. For this purpose, the content of the article is divided into three parts. In the first of them the basic ideas generally accepted in metaphysical foundationalism are formulated. These ideas do not have the status of immutable truths; they are actively debated, challenged, or defended. Those discussed variants of them, which seem to be closest to reality, are chosen in the article. The second part of the article deals with a new notion which is introduced into the argumentation. The third part contains the proof of fundamental reality actual existence based on previously defined notions and formulated statements.

\section{Result and Discussion}

Part one. The problem of fundamental reality could be considered principally solvable, provided that satisfactory answers are given to two types of questions.

1) What is meant by fundamental reality? What kind of a reality is it?

2) What arguments can be presented in favour of the existence (or vice versa - the lack of) such a reality? On the first question there is a fairly clear 
and accurate understanding of the subject. On the second question the existing answers cannot be regarded as satisfactory.

In contemporary analytic philosophy, the notion of fundamental reality is described in terms of grounding. Grounding is a relation of ontological dependence, which is sometimes characterized as "a noncausal relation of determination" "often expressed by the phrase 'in virtue of"' [1, p. 101]. In some cases $[13,7,5]$ grounding is identified with explanation. Sometimes, it is believed that explanation is only supported by grounding being distinct from it. "Grounding connects the more fundamental to the less fundamental, and thereby backs a certain form of explanation" [19, p. 122].) The last statement seems more plausible. In connection with the notion of grounding the notions of necessity, causality, priority are often used as the means of clarifying the sense of grounding. It is said to be "something like metaphysical causation" [19, p. 122]. Grounding is also identified with metaphysical priority [6]. From another point of view "we may call an in-virtue claim a statement of ontological or metaphysical ground when the conditional holds of metaphysical necessity" [7, p.38]. One can hold that grounding is manifested in some form of metaphysical necessity, metaphysical (atemporal quasi-) causation and metaphysical priority. Still it doesn't look like the optimal definition. We should prefer another one which is the definition of grounding as "a relation of complete asymmetric ontological dependence" [20, p. 3]. This definition has some preferable features being essential, general and quite metaphysical (not epistemological or logical). One should add that it is a binary relation involving two relata - a ground and something grounded.

The next step would be to identify what exactly enters into the relationship of grounding. There are two main positions on this aspect of the problem. Many researchers believe that only facts can occur in grounding relations $[12,1]$. "Facts are structured entities built up from worldly items objects, relations, connectives, quantifiers, etc. in roughly the sense in which sentences are built up from words" [15, p. 114]. What occurs in grounding relations can also be seen as the differences between facts [19, p. 132]. From another point of view grounding relata may be of various ontological categories [17]. "The intuition is just as strong regarding facts as it is regarding objects" [3, p. 5]. "Strong intuition" suggests that entities of any type may need grounding, otherwise they appear to be ungrounded. Grounded or ungrounded are all entities and so the notion of grounding concerns entities as such, entities as something existing (in any sense of this word). Therefore, from the two concepts of grounding relate the second is preferable.

For a metaphysical understanding of grounding it is also important to select one of the two types of dependence - existential or essential. The first alternative means the dependence of one entity's existence on another's existence. The second alternative proposes the dependence of one essential identity on another [9]. One should take into account that grounding is realized by any entities, and the only necessary and sufficient reason for their presence within grounding relation is their existence. If this is true, then undoubtedly the existential type of dependence looks like more pervasive for determining the nature of grounding.

One more aspect of grounding should be represented in order to make it possible to use this notion in the metaphysical fundamentalism. It is almost totally recognized that the relation of grounding is irreflexive, transitive, and asymmetric. These principles can be thus defined: a) irreflexivity - no entity grounds itself; b) transitivity - the grounded is grounded by the grounds of the grounds of the grounded; c) asymmetry - no entities can mutually ground themselves. Grounding is similar to the classical mereological relation in its irreflexivity, transitivity, and asymmetry [17, p. 376]. There is some criticism among metaphysicians of irreflexivity [8], asymmetry and transitivity of grounding [15], or all of them [14] which appeared to be not persuasive enough for the majority of philosophers dealing with the problem. Not going into discussion here we shall regard furthermore the grounding relation to be irreflexive, transitive and asymmetric. So one can assume that there is a strict partial order formed by grounding. It is represented by the chains of grounds and grounded.

In this context metaphysical foundationalism is the view that there is the initial link in every chain of grounding (I).

Initial links are composed by fundamental entities. According to Ross P. Cameron, an entity is fundamental if there is no other entities on which it depends [3, p. 5]. 
In other words, fundamental entities are ungrounded (II).

Accordingly all grounded entities are nonfundamental (III).

The doctrine of metaphysical foundationalism presupposes also that fundamental entities grounds non-fundamental. (IV)

From the statements (I)-(IV) it follows that any non-fundamental entity is grounded by fundamental entities. There is the specific notion of well-foundedness for this fact. It should be stated according to foundationalism principles that grounding is well-founded i. e. in every case it has a foundation. The hierarchy of fundamental and non-fundamental entities provides an opportunity to talk about layers of reality (the notion popularized by [16, p. 498-500]). The lower levels (beginning from the fundamental one) ground the higher levels forming the universal hierarchy.

The idea of the foundation of everything that exists is not absolutely obvious. Other variants of the metaphysical world model are possible (in particular, infinitizm - the recognition of the endless chains of entities; coherentism - the recognition of the interdependence of entities). Metaphysical fundamentalism requires proofs. As a rule, the presentation of this conception in contemporary literature is accompanied by positing some arguments. However, strictly rational arguments are lacking. The argument from intuition remains the major and the basic one. So it looks as if there is just a plausible belief in metaphysical foundation.

Still there is also some reasoning justifying such belief. The main arguments are these.

1. The argument from reality. Every nonfundamental entity is real due to some other entities. Eventually there must be the source of reality and it cannot obtain reality from something else as in that case it wouldn't be the real source. "There must be a ground of being. If one thing exists only in virtue of another, then there must be something from which the reality of the derivative entities ultimately derives" [18, p. 37].

2. The argument from composition. Every nonfundamental level of reality is the result of the composition of some grounding entities. There must be something out of which everything is built and this something cannot be built of something else as in that case there would be no exact building blocks of the world. This view is held by mereological foundationalism namely mereological pluralism admitting the existence of mereological simples [3].

3. The argument from completeness. According to J. Schaffer, "The first premise of the argument is that the basic entities must be complete, in the sense of providing a blueprint for reality. More precisely, a plurality of entities is complete if and only if duplicating all these entities, while preserving their fundamental relations, metaphysically suffices to duplicate the cosmos and its contents. The second premise of the argument from completeness is that any plurality of entities that did not cover the cosmos would be incomplete. They would fail to provide a blueprint with respect to the portion left uncovered" [18, p. 39].

The expressed arguments seem to be not quite convincing. Basically, they appeal to intuition, more precisely, to intuitive, sensory, visual representations of the world. Opponents tend to use this as a theoretical weakness in the debates with metaphysical foundationalism supporters. The most rigid assessment is given by C. Daly, for whom grounding as a primitive notion is "unintelligible" [4, p. 81].

Counterarguments of anti-fundamentalists are based, in particular, on the assumption that the belief in metaphysical foundation lies greatly in attempts to imagine the endless chain of entities, though there is no need in such imagination. According to R. Bliss "infinite grounding regresses are not necessarily vicious", as "at each level of the regress the phenomena invoked to explain the phenomena at the level above are different" [2, p. 179]. Another anti-fundamentalist assumption is that grounding is represented by metaphysical foundationalists as a process which, according to their opponents, is a mistake. Foundationalism intuition is "taking too seriously the temporal metaphor suggested by "priority"' on Ross P. Cameron's opinion [3, p. 9].

Metaphysical foundationalism looks unsatisfactory also from the naturalistic point of view. According to 'Principle of Naturalistic Closure' formulated by J. Ladyman and D. Ross, "Any new metaphysical claim that is to be taken seriously at time $t$ should be motivated by, and only by, the service it would perform, if true, in showing how two or more specific scientific hypotheses, at least one of which is drawn from fundamental physics, jointly explain more than the sum of 
what is explained by the two hypotheses taken separately" [10, p. 30]. K. McKenzie is convinced that the state of affairs within metaphysical foundationalism is deeply dissatisfying from a naturalistic point of view [11].

The arguments of anti-fundamentalists should be acknowledged as serious. As a result of such criticism, alternative concepts seem to be at least not less convincing than the concept of metaphysical fundamentalism. At the same time, their justification demonstrates no more plausibility than that of their opponents. The defects of the latter can be attributed to its alternatives as well.

Part two. The aim of the article is not to go into controversy with anti-fundamentalism. Rather, it is an attempt to show another way of justification of metaphysical fundamentalism. The argumentation will proceed from the above-formulated standard positions:

1. All entities (anything that exists) are the parts of the grounding relation.

2. Grounding is a relation between entities, the existence of one of which is necessary for the existence of another. The former entity is called "the ground", the latter is called "the grounded".

3. Grounding is irreflexive, transitive, and asymmetric.

4. The entity which has no ground is called "fundamental". (It doesn't mean that such entities really exist).

5. The entity which is grounded is called "unfundamental".

Let's introduce a new notion - the notion of the state of the world.

It is unlikely that there are now supporters of Parmenides, so we assume it to be generally accepted that the world is heterogeneous. The world in this sense is a collection of entities. The question is what kind of collection can be identified with the world? It turns out that it is possible for different collections.

For example, the world at every moment of cosmic time is something united and whole. This whole is not just a part of the world but the world itself in some chronological position. So we have the same world in its different time states.

The state of the world can be imagined as a collection of causes and effects. Naturally, this collection is not unique there are different collec- tions at different points in time. It should be noted that although causality is associated with time, the causal state of the world is not the same as its temporary state.

The state of the world can be imagined as a collection of its structural elements. It goes about the elements of the one and the same structural level. The world, perhaps, is a collection of elementary particles and fields. The world, on the other hand, is a collection of chemicals. In addition, it is a collection of macro-objects. All this can be called the structural states of the world.

The states of the world may also reflect similarity and difference in everything that exists. Taxonomic division of entities splits them into closed collections and each level of this division covers the whole world. Let us assume that we know all generic entities of a definite level and all their species. Then we find that both collections of entities - genera and species - overlap, doubling the world. These collections obviously represent two distinct states of the world which can be called taxonomic.

Thus experience gives us the opportunity to describe the world through different collections of entities. Each collection represents one and the same - our actual world (one can say: the world observed with one of its facets). And so a collection of entities which constitutes the world as a whole will be expressed by the term "a state of the world".

There are probably other variants of states of the world in addition to those given as examples but it is not essential for us here. It is important that all states have something in common which is covered by the general notion. To define the pure notion of the state of the world it is necessary to generalize the above examples. As a result we come to an exclusively existential characteristic of the world. The state of the world should be understood as the totality of all entities qua entities that is something characterized by its existence. The existential state of the world could be considered to be the basis of more specific manifestations (temporary, causal or other).

It should be added that the state of the world differs from the layer of reality, since a layer of reality not necessarily covers the whole world. One more principal distinction: the states of the world are not the same as the possible worlds. 
Firstly, the states of the world are actual, not possible; secondly, they are states of the one and the same world. Now it is possible to reformulate the basic statements of metaphysical fundamentalism taking into account the new notion.

2.1. Grounding is a relation between the ground and the grounded. The grounded is an entity that is present in all states of the world where there is its ground. The ground is an entity that is present in some states of the world with the grounded and in some without it. From this we can conclude that all entities belonging to the same state of the world with a grounded entity eventually are the ground of the latter. This is quite plausible. Different entities are not the same in this case because their structures of grounding are different. On the other hand, we can say that if qualitatively different states of the world are numerous enough, then for any two entities there exists one and only one common set of states of the world. So the direct ground of each grounded entity is only one of other entities.

3.1. Grounding, reformulated with the notion of the state of the world in mind, is still irreflexive, transitive, and asymmetric.

Irreflexivity. In order to be reflexive, that is, to ground itself one and the same entity should be present in all states of the world together with itself and be in some states of the world in which it is not present. Obviously it is impossible. Therefore the relation of grounding is irreflexive.

Transitivity. Suppose there are entities X, Y, and Z. The first entity is the ground of the second, the second is the ground of the third. Z exists in all states of the world in which there is Y. Y exists in all states of the world in which there is X. Consequently, $\mathrm{Z}$ exists in all states of the world in which there is $X$. There are such states of the world in which there is no $\mathrm{Y}$, but there is X. But where there is no $\mathrm{Y}$ one cannot find $\mathrm{Z}$ either. So there are states of the world in which $X$ exists, and there is no Z. From this it follows that $\mathrm{Z}$ is the ground of $X$. Transitivity is preserved in relations of grounding, provided the states of the world are taken into account.

Asymmetry. Suppose that two entities A and B are symmetric, that is mutually ground each other. For this A should exist in all states of the world along with $B$ and be in some of states where $B$ is missing. Similarly, B should exist in all states of the world along with $A$ and be in some of states where $\mathrm{A}$ is missing. So A must be in all states where there is B and must not be in all these states. The same is with B. The inconsistency of these statements is obvious, it is impossible to reconcile them. It follows that the relation of grounding is asymmetric.

4.1. A fundamental entity is an entity which is present in all states of the world. The complete collection of such entities (which may consist of one entity) is the only fundamental reality because no other entities are present in all states of the world.

5.1. An unfundamental entity is an entity which is present not in all states of the world.

Are these statements sufficient to conclude that fundamental reality in a sense produces all unfundamental entities? Or at least that everything unfundamental depends on it? The most brief and evident argument is such. Since without fundamental reality nothing exists, and without any unfundamental entity fundamental reality exists, it is obvious that everything unfundamental at least depends on fundamental reality or at most is produced by it. However (as it is usually claimed in modern metaphysical fundamentalism), the bonds between the ultimate ground and the grounded are not causal. So even if we could speak about producing or generating of the whole world by its fundamental basis it wouldn't go about producing or generating in causal sense.

The definition of fundamental and nonfundamental reality, of course, is not yet the proof of their existence. This is a purely theoretical construct. However, we already have all the necessary prerequisites for the proof of the existence of fundamental reality. There is an empirical base which is filled with diverse entities (we do not question neither the existence of something, nor the variety of existing entities). There is the notion of grounding more generally defined. This is sufficient for the required proof.

Proof is required only in the case when one admits the existence of at least some entities which have grounds (in extreme case - all). In the opposite case, all reality is fundamental. Such a view is logically valid. But it entails that the world and everything in the world is absolutely accidental. This doesn't look plausible. (A more thorough refutation of this understanding of the world is not considered here). 
Suppose that grounded entities exist and grounding is irreflexive, transitive, and asymmetric. Let's single out one of entities together with all its grounds existing in different states of the world. We get a sequence of parts of states of the world, consisting of a given terminal entity and all its grounds. Such sequence must include all actual states of the world. Otherwise it should be supposed that the fundamental ground of a given entity is not present in all states of the world. Then it is not fundamental because there are entities which are present in all states of the world together with the supposed ground being also present in the states of the world lacking it and so according to the statement (2.1) the supposed ground is grounded. Let's pay attention now to parts of states of the world of which the above sequences consist. It is obvious that the part of a state of the world in which a grounded entity and its grounds coexist is more complex, than that one in which there are only grounds. (Owing to transitivity, at any grounded state of the world there are also all its grounds). Therefore, the sequence of parts of the states of the world, going from the grounded to its grounds is a sequence going from the more complex to the more simple.

The sequence of simplifications implies the existence of its limit in the form of something absolutely simple. Thus it differs from mereological sequence of parts and wholes. The notion of the part does not imply the limit of a sequence. The transition from parts to parts of parts can be limitless. The notion of the simple indicates the completion of simplification. Simplification is related to its limit. The notions of the complex and the simple are correlative. One of them doesn't make sense without another. If there is something simple, it is the limit of simplification (even if we assume that there is infinite sequence of simplifications). The absence of anything simple makes pointless the talk about simplification. It makes sense to speak only about the transition to entities with some parts lacking (not to more simple entities).

A sequence of grounds (in other words, a sequence of parts of states of the world consisting in grounds), as has been shown, is a simplification, so it has a limit. The limit of a chain of grounds and grounded is a maximally simple ground which cannot be more simple, in other words, has no foundation but itself. Thus, it can be argued that any non-fundamental entity is a final member of the sequence, the initial member of which is a fundamental essence. All nonfundamental entities are reduced to fundamental.

Is the opposite conclusion correct, namely, that all fundamental entities ground nonfundamental? Suppose that there are entities that are fundamental and are not grounds for nonfundamental entities. Then they are not present in all states of the world where there are nonfundamental entities. It follows from the assertion (2.1). But it means that they are nonfundamental, as it follows from assertion (4.1).

It is proven that in our world there is a fundamental reality (consisting of one or multiple entities), and that it is the basis of all nonfundamental realities.

\section{Conclusion}

The conception of metaphysical fundamentalism has been revised in the article. The set of initial principles was formulated and refined. The notion of the state of the world was introduced in order to find a new way of argumentation. The correspondence of the new notion and the initial principles of metaphysical fundamentalism have been confirmed. The proof of fundamental reality existence has been represented based on formulated principles and empirical data.

\section{References}

1. Audi, P. (2012). A clarification and defense of the notion of grounding. In F. Correia, \& B. Schnieder (Eds.), Metaphysical Grounding: Understanding the Structure of Reality (pp. 101-121). Cambridge: Cambridge University Press.

2. Bliss, R. (2012). Against Metaphysical Foundationalism (Doctoral thesis, University of Victoria). Retrieved from https://sites.google.com/site/rickibliss/home/research

3. Cameron, R. P. (2008). Turtles all the way down: Regress, priority and fundamentality. Philosophical Quarterly, 58(230), 1-14. doi: 10.1111/j.1467-9213.2007.509.x 
4. Daly, Ch. (2012). Scepticism about Grounding. In F. Correia, \& B. Schnieder (Eds.), Metaphysical Grounding: Understanding the Structure of Reality (pp. 81-100). Cambridge: Cambridge University Press.

5. Dasgupta, Sh. (2014). On the Plurality of Grounds. Philosophers' Imprint, 14(20), 1-28.

6. Dixon, T. S. (2016). What Is the Well-Foundedness of Grounding? Mind, 125(498), 439-468. doi: $10.1093 / \mathrm{mind} / \mathrm{fzv} 112$

7. Fine, K. (2012). Guide to Ground. In F. Correia, \& B. Schnieder (Eds.), Metaphysical Grounding: Understanding the Structure of Reality (pp. 37-80). Cambridge: Cambridge University Press.

8. Jenkins, C. S. (2011). Is Metaphysical Dependence Irreflexive? The Monist, 94(2), 267-276. doi: $10.5840 /$ monist201194213

9. Koslicki, K. (2013). Ontological Dependence: An Opinionated Survey. In B. Schnieder, M. Hoeltje, \& A. Steinberg (Eds.), Varieties of Dependence: Ontological Dependence, Grounding, Supervenience, Response-Dependence (Basic Philosophical Concepts) (pp. 31-64). Munich: Philosophia Verlag.

10. Ladyman, J., \& Ross, D. (2007). Every Thing Must Go: Metaphysics Naturalized. Oxford: Oxford University Press.

11. McKenzie, K. (2011). Arguing against fundamentality. Studies in History and Philosophy of Science. Part B: Studies in History and Philosophy of Modern Physics, 42(4), 244-255. doi: 10.1016/j.shpsb.2011.09.002

12. Raven, M. J. (2012). In Defence of Ground. Australasian Journal of Philosophy, 90(4), 687-701. doi: 10.1080/00048402.2011.616900

13. Raven, M. J. (2015). Ground. Philosophy Compass, 10(5), 322-333. doi: 10.1111/phc3.12220

14. Rodriguez-Pereyra, G. (2015). Grounding is not a strict order. Journal of the American Philosophical Association, 1(3), 517-534. doi: 10.1017/apa.2014.22

15. Rosen, G. (2010). Metaphysical Dependence: Grounding and Reduction. In B. Hale, \& A. Hoffmann (Eds.), Modality: Metaphysics, Logic, and Epistemology (pp. 109-136). Oxford: Oxford University Press.

16. Schaffer, J. (2003). Is there a fundamental level? Noûs, 37(3), 498-517.

17. Schaffer, J. (2009). On what grounds what. In D. Manley, D. J. Chalmers, \& R. Wasserman (Eds.), Metametaphysics: New Essays on the Foundations of Ontology (pp. 347-383). Oxford: Oxford University Press.

18. Schaffer, J. (2010). Monism: The Priority of the Whole. Philosophical Review, 119(1), 31-76. doi: 10.1215/00318108-2009-025

19. Schaffer, J. (2012). Grounding, transitivity, and contrastivity. In F. Correia, \& B. Schnieder (Eds.), Metaphysical Grounding: Understanding the Structure of Reality (pp. 122-138). Cambridge: Cambridge University Press.

20. Wilson, J. M. (2012). Fundamental determinables. Philosophers' Imprint, 12(4), 1-17.

(C) A. Kulieshov

Received 2016-11-24, Accepted 2016-12-04, Published online 2016-12-06 


\title{
Метафизический фундаментализм: новая форма
}

\author{
Кулешов Александр Вадимович \\ Черкасский государственный технологический университет, \\ кафедра философских и политических наук, кандидат философских науки, доцент, Украина
}

\begin{abstract}
Аннотация. Статья предлагает новый набор метафизических аргументов в пользу фундаментальной реальности. Для этой цели вводится понятие состояния мира. Учитывается стандартная основополагающая концепция метафизического фундаментализма. Подтверждается соответствие нового понятия и исходных принципов метафизического фундаментализма. На основе сформулированных принципов и эмпирических данных представляются доказательства существования фундаментальной реальности.
\end{abstract}

Ключевые слова: метафизический фундаментализм, основополагающая связь, сущность, состояние мира, фундаментальная реальность.

\section{удК 141}

LCC Subject Category: BF1-990

DOI: http://dx.doi.org/10.22178/pos.17-3

\section{Список информационных источников}

1. Audi P. A clarification and defense of the notion of grounding. Metaphysical Grounding: Understanding the Structure of Reality / eds. F. Correia, B. Schnieder. Cambridge : Cambridge University Press, 2012, P. 101-121.

2. Bliss R. Against Metaphysical Foundationalism: doctoral thesis, University of Victoria. URL: https://sites.google.com/site/rickibliss/home/research

3. Cameron R. P. Turtles all the way down: Regress, priority and fundamentality. Philosophical Quarterly. 2008. № 58(230). P. 1-14. doi: 10.1111/j.1467-9213.2007.509.x

4. Daly Ch. Scepticism about Grounding. Metaphysical Grounding: Understanding the Structure of Reality / eds. F. Correia, B. Schnieder. Cambridge: Cambridge University Press, 2012. P. 81-100.

5. Dasgupta Sh. On the Plurality of Grounds. Philosophers' Imprint. 2014. № 14(20). P. 1-28.

6. Dixon T. S. What Is the Well-Foundedness of Grounding? Mind. 2016. № 125(498). P. 439-468. doi: 10.1093/mind/fzv112

7. Fine K. Guide to Ground. Metaphysical Grounding: Understanding the Structure of Reality / eds. F. Correia, B. Schnieder. Cambridge: Cambridge University Press, 2012. P. 37-80.

8. Jenkins C. S. Is Metaphysical Dependence Irreflexive? The Monist. 2011. № 94(2). P. 267-276. doi: 10.5840/monist201194213

9. Koslicki K. (2013). Ontological Dependence: An Opinionated Survey. Varieties of Dependence: Ontological Dependence, Grounding, Supervenience, Response-Dependence (Basic Philosophical Concepts) / eds. B. Schnieder, M. Hoeltje, A. Steinberg. Munich: Philosophia Verlag, 2013. P. 3164.

10. Ladyman J., Ross D. Every Thing Must Go: Metaphysics Naturalized. Oxford: Oxford University Press, 2007. 359 p.

11. McKenzie, K. Arguing against fundamentality. Studies in History and Philosophy of Science. Part B: Studies in History and Philosophy of Modern Physics. 2011. № 42(4). P. 244-255. doi: 10.1016/j.shpsb.2011.09.002

12. Raven M. J. In Defence of Ground. Australasian Journal of Philosophy. 2012. № 90(4). P. 687-701. doi: 10.1080/00048402.2011.616900

13. Raven M. J. Ground. Philosophy Compass. 2015. № 10(5). P. 322-333. doi: 10.1111/phc3.12220

14. Rodriguez-Pereyra G. Grounding is not a strict order. Journal of the American Philosophical Association. 2015. № 1(3). P. 517-534. doi: 10.1017/apa.2014.22 
15. Rosen G. (2010). Metaphysical Dependence: Grounding and Reduction. Modality: Metaphysics, Logic, and Epistemology / eds. B. Hale, A. Hoffmann. Oxford: Oxford University Press, 2010. P. 109-139.

16. Schaffer J. Is there a fundamental level? Noûs. 2003. № 37(3). P. 498-517.

17. Schaffer J. (2009). On what grounds what. Metametaphysics: New Essays on the Foundations of Ontology / eds. D. Manley, D. J. Chalmers, R. Wasserman. Oxford: Oxford University Press, 2009. P. 347-383.

18. Schaffer J. Monism: The Priority of the Whole. Philosophical Review. 2010. № 119(1). P. 31-76. doi: 10.1215/00318108-2009-025

19. Schaffer, J. (2012). Grounding, transitivity, and contrastivity. Metaphysical Grounding: Understanding the Structure of Reality / eds. F. Correia, B. Schnieder. Cambridge : Cambridge University Press, 2012. P. 122-138.

20. Wilson J. M. Fundamental determinables. Philosophers' Imprint. 2012. № 12(4). P. 1-17.

(C) А. В. Кулешов

Статья получена 24.11.2016, принята 04.12.2016, опубликована оnline 06.12.2016 